\title{
Cultivares de Brachiaria brizantha sob diferentes disponibilidades hídricas em Neossolo Flúvico
}

\author{
Bruna E. Kroth ${ }^{1}$, Edna M. Bonfim-Silva ${ }^{1}$, Tonny J. A. da Silva ${ }^{1}$, Marcio Koetz $^{1}$ \& Alessana F. Schlichting ${ }^{1}$ \\ ${ }^{1}$ Instituto de Ciências Agrárias e Tecnológicas/Universidade Federal de Mato Grosso. Rondonópolis, MT. E-mail: bru_ellusa@hotmail.com; \\ embonfim@hotmail.com (Autora correspondente); tonnyjasilva@hotmail.com; marciokoetz@yahoo.com.br; alessanamt@gmail.com
}

\section{Palavras-chave: \\ estresse hídrico \\ marandu \\ piatã \\ solo alagado \\ xaraés}

\begin{abstract}
R E S U M O
Propôs-se, com este trabalho, estabelecer a tolerância ao déficit hídrico e ao alagamento do solo na produção de folhas e colmos de três cultivares de Brachiaria brizantha cultivadas em Neossolo Flúvico. O experimento foi realizado em casa de vegetação cujas unidades experimentais foram vasos plásticos com capacidade de solo de $4,2 \mathrm{dm}^{3}$. O delineamento experimental foi inteiramente casualizado em esquema fatorial $3 \times 3$, com três cultivares de Brachiaria brizantha (Marandu, Piatã e Xaraés) e três disponibilidades hídricas, sendo solo alagado $(0 \mathrm{kPa})$, capacidade de campo (10 kPa, tratamento controle) e déficit hídrico $(50 \mathrm{kPa})$, em 5 repetições. O solo utilizado foi o Neossolo Flúvico. Para avaliação foram realizados três cortes nos quais foram avaliadas massa seca de folhas, massa seca de colmos e relação folha/colmo. Os dados foram submetidos à análise de variância pelo teste $\mathrm{F}$ e, quando significativos, foi aplicado o teste de Tukey até 0,05 de probabilidade. As cultivares de Brachiaria brizantha (Marandu, Piatã e Xaraés) apresentaram susceptibilidade ao déficit hídrico em que a cultivar Marandu foi a única resistente ao alagamento do solo com desenvolvimento expressivo nos três cortes realizados.
\end{abstract}

\section{Key words:}

water deficit

Marandu

Piatã

flooded soil

Xaraés

\section{Brachiaria brizantha cultivars grown under different water availability in Entisol}

\begin{abstract}
A B S T R A C T
The objective was to establish the tolerance to drought and flooding in the production of leaves and stems of three B. brizantha cultivars in Fluvisol. The experiment was conducted in a greenhouse, where the experimental units were plastic pots with capacity of 4.2 $\mathrm{dm}^{3}$. The experimental design was completely randomized in a factorial $3 \mathrm{x} 3$ with three cultivars of Brachiaria brizantha (Marandu, Piatã and Xaraés) and three water availability, and, waterlogged soil $(0 \mathrm{kPa})$, field capacity (10 kPa, control) and water deficit (50 kPa) with 5 repetitions. The soil used was Entisol. Three cuttings were performed which were evaluated for dry mass of leaves, dry mass of stems and leaf/stem ratio. Data were subjected to analysis of variance by $\mathrm{F}$ test, and when significant Tukey test at 0.05 probability was used. The cultivars of Brachiaria brizantha (Marandu, Piata and Xaraés) were susceptible to drought, being the Marandu the only resistant to flooding, with significant development in the three cuttings.
\end{abstract}




\section{INTRODUÇÃO}

O Brasil é um grande produtor de carne e leite com criação de bovinos a pasto obtendo um rebanho de aproximadamente 212 milhões de cabeças além de possuir ambientes edafoclimáticos com excelente potencial para aumentar ainda mais esta participação no mercado mundial (IBGE, 2011). Segundo Vitor et al. (2009) a pastagem é a forma mais prática e econômica de alimentação de bovinos e constitui a base de sustentação da pecuária do Brasil.

O Brasil abateu 31.117.549 bovinos em 2012 e o Estado de Mato Grosso lidera esta estatística com participação nacional de $16,1 \%$ no abatimento. A perspectiva de crescimento deste setor é de 22,5\% até 2023 (MAPA, 2013) para atender à demanda do mercado brasileiro e internacional.

Segundo Jones (1979) o principal obstáculo à produção animal nas regiões tropicais e subtropicais tem sido o suprimento irregular de forragem durante o ano, sobretudo em razão do estresse hídrico sazonal ocasionado por secas e alagamentos do solo. Para tanto, há necessidade de se identificar a tolerância e a susceptibilidade das pastagens às condições de estresse hídrico visando à recomendação de cultivares que expressem o máximo de seu potencial produtivo em condições de déficit hídrico e alagamento do solo.

Áreas de pastagens sujeitas a veranicos ou secas estacionais e alagamento são comuns em quase todo o território nacional. As espécies do gênero Brachiaria são as mais usadas no estabelecimento, na formação e na recuperação de pastagens no Brasil (Zimmer \& Euclides, 2000). Todavia, poucos são os estudos envolvendo as características que conferem adaptação à seca ou ao alagamento a essas espécies.

Neste contexto, condições temporárias ou permanentes de alagamento (umedecimento e secagem) ou encharcamento (saturação com água) do solo são problemas que podem trazer sérios prejuízos para o desenvolvimento agropecuário (DiasFilho \& Lopes, 2012).

O déficit na disponibilidade de oxigênio é o principal fator de estresse em solos com excesso de água. Nas plantas, o impacto do excesso de água no solo é, na maioria dos casos, sentido diretamente pelas raízes e indiretamente pela parte aérea (Dias-Filho \& Lopes, 2012) induzindo, à clorose, murchamento prematuro e queda da capacidade fotossintética e, consequentemente, diminuição no crescimento (Visser et al., 2003).

Por outro lado e segundo Duarte et al. (2012) o déficit hídrico é o resultado (negativo) do balanço hídrico em que o total de água que entra no sistema via precipitação é menor que a quantidade total de água perdida pela evaporação e pela transpiração pelas plantas. A perda de água do tecido da planta produz efeitos diretos, como redução do potencial químico ou atividade da água, além de aumentar a concentração de macromoléculas, como os fosfolipídios poli-insaturados e de solutos de baixos pesos moleculares (Carvalho et al., 2011).
O conhecimento das respostas da planta forrageira em condições de estresse hídrico é de grande importância para auxiliar no entendimento dos efeitos do período seco e chuvoso na produção de forragem, possibilitando o uso de práticas de manejo para melhor utilização do pasto durante esses períodos (Araújo et al., 2010). Assim, objetivou-se estabelecer a tolerância e a susceptibilidade ao déficit hídrico e ao alagamento do solo na produção de folhas e colmos de três cultivares de Brachiaria brizantha (Marandu, Piatã e Xaraés) cultivadas em Neossolo Flúvico.

\section{Material e Métodos}

O experimento foi realizado em casa de vegetação localizada a $16^{\circ} 28^{\prime}$ latitude Sul, $50^{\circ} 34^{\prime}$ longitude Oeste e altitude de 284 $\mathrm{m}$. Utilizou-se delineamento inteiramente casualizado em esquema fatorial $3 \times 3$, sendo três cultivares de Brachiaria brizantha (Marandu, Piatã e Xaraés) e três disponibilidades hídricas do solo (solo alagado, capacidade de campo e déficit hídrico) com cinco repetições.

O solo alagado caracterizou-se com uma lâmina de $4 \mathrm{~cm}$ de água sob a superfície do solo. A capacidade de campo e o déficit hídrico foram caracterizados pelas tensões de $10 \mathrm{kPa}$ (tratamento controle) e $50 \mathrm{kPa}$ (déficit hídrico) respectivamente.

As unidades experimentais foram vasos com capacidade de solo de $4,2 \mathrm{dm}^{3}$. O solo utilizado foi o Neossolo Flúvico (EMBRAPA, 2006), coletado na região de Rondonópolis-MT, na camada de $0-0,20 \mathrm{~m}$ de profundidade e posteriormente peneirado em malha $4 \mathrm{~mm}$ para inserção nas unidades experimentais. Amostras deste solo foram retiradas para caracterização química e granulométrica, conforme metodologia da EMBRAPA (1997) (Tabela 1). A saturação por bases foi elevada para 50\%, incubando calcário (PRNT $80,3 \%$ ) durante 30 dias mantendo o solo a $60 \%$ da capacidade máxima de retenção de água do solo neste período.

No controle das disponibilidades hídricas a reposição evapotranspirada foi realizada com base na leitura tensiométrica, razão por que se necessitou da construção da curva de retenção de água no solo. A metodologia para a construção da curva de retenção de água no solo foi baseada e adaptada em trabalhos realizados por Almeida et al. (2010).

Nesta metodologia três unidades experimentais foram utilizadas para construção da curva de umidade. Em cada unidade instalou-se um tensiômetro. O solo dos vasos foi saturado por capilaridade durante $24 \mathrm{~h}$ e inserido em bandejas de polietileno adicionando-se-lhe água até dois terços da altura dos vasos; após este período os vasos foram retirados das bandejas até ocorrer a drenagem natural do excesso de água no solo, pelo tempo de $24 \mathrm{~h}$. Ao cessar a drenagem foram realizadas as pesagens dos vasos e as leituras tensiométricas concomitantemente, a cada cinco horas. Realizou-se este procedimento durante 10 dias com vista à coleta dos dados.

Tabela 1. Caracterização química e granulométrica de amostra do Neossolo Flúvico, na camada de 0-0,20 m de profundidade

\begin{tabular}{|c|c|c|c|c|c|c|c|c|c|c|c|}
\hline $\mathrm{pH}$ & $\mathbf{P}$ & $K$ & $\mathrm{Ca}$ & $\mathrm{Mg}$ & $\mathrm{H}$ & CTC & \multirow{2}{*}{$\begin{array}{l}\mathrm{m} \\
\%\end{array}$} & M.O & Areia & Silte & Argila \\
\hline $\mathrm{CaCl}_{2}$ & \multicolumn{2}{|c|}{$\mathrm{mg} \mathrm{dm^{-3 }}$} & \multicolumn{4}{|c|}{$\mathrm{cmol}_{\mathrm{c}} \mathrm{dm}^{-3}$} & & \multicolumn{4}{|c|}{$\mathrm{g} \mathrm{kg}^{-1}$} \\
\hline 4,2 & 6,0 & 51 & 0,6 & 0,4 & 3,5 & 5,3 & 38,3 & 7,6 & 780 & 100 & 120 \\
\hline
\end{tabular}


Após este período foram realizados os cálculos de umidade do solo para traçar a curva de retenção de água no solo (Figura 1); esta curva foi construída com três repetições adotando-se a média entre os valores obtidos.

Para a condução do experimento foi instalado um tensiômetro por unidade experimental. Os tensiômetros foram instalados no centro do vaso a uma profundidade de 0,10 m, com o auxílio de um trado de rosca. Após o início dos tratamentos a água evapotranspirada foi reposta manualmente, diariamente, tomando-se como base as leituras das tensões de água no solo feitas por um tensímetro digital acoplado aos tensiômetros. Para o tratamento com solo alagado a reposição foi realizada também manualmente, mantendo-se o nível de água $4 \mathrm{~cm}$ acima da superfície do solo.

Foram aplicados $150 \mathrm{mg} \mathrm{dm}^{-3}$ de fósforo e $100 \mathrm{mg} \mathrm{dm}^{-3}$ de potássio na semeadura utilizando-se superfosfato simples e cloreto de potássio, respectivamente. A adubação com nitrogênio $\left(200 \mathrm{mg} \mathrm{dm}^{-3}\right.$ ) utilizando ureia foi parcelada em quatro aplicações iguais (na semeadura e aos 4, 8 e 11 dias após a semeadura). Três cortes foram realizados e após cada corte, foram aplicadas adubações de manutenção com nitrogênio e potássio; o potássio foi aplicado em dose única e o nitrogênio foi parcelado em quatro aplicações.

A semeadura foi realizada diretamente nos vasos deixando-se três plantas por vaso; quando as plantas atingiam altura média de $10 \mathrm{~cm}$ foram iniciados os tratamentos com disponibilidades hídricas garantindo que as plantas estivem estabelecidas. Para o início dos tratamentos com as disponibilidades hídricas necessitou-se de 5 dias para ajustar as umidades do solo.

A coleta dos dados foi subdividida em três avaliações cada qual acompanhada de um corte; aos 45 dias da instalação dos tratamentos foi realizado o primeiro corte das plantas a cinco centímetros da superfície do solo coletando-se apenas a parte aérea para possibilitar a rebrota, conforme descrito por Silva et al. (2007). Aos 30 dias após o primeiro corte foi realizado o segundo corte, também a cinco centímetros da superfície do solo enquanto o terceiro e último corte também foi aos 30 dias após o segundo corte sendo este rente ao solo. As variáveis analisadas foram massa seca de folhas, massa seca de colmos e relação folha/colmo.

Os dados foram transformados para obtenção da normalidade e homogeneidade das variâncias por $\sqrt{\mathrm{x}}+1$, com

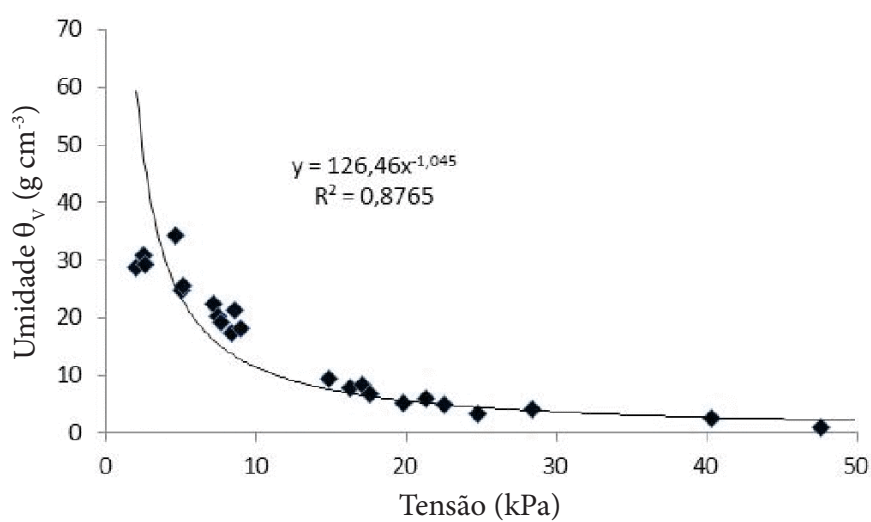

Figura 1. Curva de retenção de água em Neossolo Flúvico utilizado na condução do experimento. Umidade do solo $\left(\mathrm{g} \mathrm{cm}^{-3}\right)$ em função da tensão de água no solo $(\mathrm{kPa})$ auxílio do programa estatístico Assistat 7.7 (Silva \& Azevedo, 2002); em seguida, os dados foram submetidos à análise de variância pelo teste $\mathrm{F}$ e, quando significativos, aplicou-se o teste Tukey a 0,05 de probabilidade utilizando-se o programa estatístico SISVAR.

\section{Resultados e Discussão}

Houve interações significativas a 0,01 de probabilidade nos primeiro, segundo e terceiro cortes entre as disponibilidades hídricas do solo e as cultivares de Brachiaria brizantha em relação à massa seca de folhas (Tabela 2) e de colmos (Tabela 3 ), porém ocorreu efeito isolado das disponibilidades hídricas do solo a 0,01 de probabilidade para a relação folha/colmo nos primeiro e terceiro cortes (Tabela 4).

No primeiro corte das gramíneas forrageiras observou-se decréscimo da massa seca de folhas das cultivares de Brachiaria brizantha no solo com déficit hídrico $(50 \mathrm{kPa})$ e no solo em

Tabela 2. Massa seca de folhas $\left(\mathrm{g} \mathrm{vaso}^{-1}\right)$ nos primeiro, segundo e terceiro cortes de cultivares de Brachiaria brizantha sob diferentes disponibilidades hídricas do solo

\begin{tabular}{lccc}
\hline \multirow{2}{*}{ Cultivar } & \multicolumn{3}{c}{ Disponibilidade hídrica } \\
\cline { 2 - 4 } Marandu & Alagado & $\begin{array}{c}\text { Capacidade de campo } \\
1^{\circ} \mathrm{Corte}\end{array}$ & Déficit hídrico \\
Piatã & $11,84 \mathrm{Ab}$ & $20,26 \mathrm{Aa}$ & $1,07 \mathrm{Ac}$ \\
Xaraés & $6,41 \mathrm{Bb}$ & $13,89 \mathrm{Ba}$ & $6,41 \mathrm{Ac}$ \\
CV (\%) & $4,54 \mathrm{Bb}$ & $18,98 \mathrm{Aa}$ & $4,54 \mathrm{Ab}$ \\
\hline \multicolumn{4}{c}{10,72} \\
Marandu & $18,21 \mathrm{Aa}$ & $19,25 \mathrm{Aa}$ \\
Piatã & $8,85 \mathrm{Bb}$ & $17,52 \mathrm{Aa}$ \\
Xaraés & $4,49 \mathrm{Aa}$ & $23,46 \mathrm{Aa}$ \\
CV (\%) & \multicolumn{3}{c}{$0,32 \mathrm{Ab}$} \\
\hline & 19,87 & $0,97 \mathrm{Bb}$ \\
Marandu & $17,88 \mathrm{Aa}$ & $3^{\circ} \mathrm{Corte}$ \\
Piatã & $6,91 \mathrm{Bb}$ & $15,54 \mathrm{Aa}$ \\
Xaraés & $4,12 \mathrm{Bb}$ & $18,26 \mathrm{Aa}$ \\
CV (\%) & \multicolumn{3}{c}{$0,41 \mathrm{Ab}$} \\
\hline
\end{tabular}

Médias seguidas pela mesma letra maiúscula para cultivares de Brachiaria brizantha e minúscula para disponibilidades hídricas não diferem entre si pelo teste Tukey a 0,05 de probabilidade; CV (\%) - Coeficiente de variação

Tabela 3. Massa seca de colmos $\left(\mathrm{g}\right.$ vaso $\left.^{-1}\right)$ nos primeiro, segundo e terceiro cortes de cultivares de Brachiaria brizantha sob diferentes disponibilidades hídricas do solo

\begin{tabular}{|c|c|c|c|}
\hline \multirow{2}{*}{ Cultivar } & \multicolumn{3}{|c|}{ Disponibilidade hídrica } \\
\hline & Alagado & Capacidade de campo & Déficit hídrico \\
\hline \multicolumn{4}{|c|}{$1^{\circ}$ Corte } \\
\hline Marandu & $7,97 \mathrm{Ab}$ & $11,82 \mathrm{Aa}$ & $0,21 \mathrm{Ac}$ \\
\hline Piatã & $2,73 \mathrm{Bb}$ & $8,96 \mathrm{ABa}$ & $0,56 \mathrm{Ab}$ \\
\hline Xaraés & $2,03 \mathrm{Bb}$ & 7,93 Ba & $0,19 \mathrm{Ab}$ \\
\hline \multirow{2}{*}{\multicolumn{4}{|c|}{$\frac{14,27}{2^{\circ} \text { Corte }}$}} \\
\hline & & & \\
\hline Marandu & $10,05 \mathrm{Aa}$ & $6,75 \mathrm{Aa}$ & $0,03 \mathrm{Ab}$ \\
\hline Piatã & $5,32 \mathrm{Bb}$ & $9,7 \mathrm{Aa}$ & $0,27 \mathrm{Ac}$ \\
\hline Xaraés & $2,26 \mathrm{Cb}$ & $7,38 \mathrm{Aa}$ & $0,015 \mathrm{Ab}$ \\
\hline \multirow{2}{*}{\multicolumn{4}{|c|}{$\frac{19,06}{3^{\circ} \text { Corte }}$}} \\
\hline & & $3^{\circ}$ Corte & \\
\hline Marandu & $11,92 \mathrm{Aa}$ & 7,79 Ba & $0,57 \mathrm{Ab}$ \\
\hline Piatã & $4,95 \mathrm{Bb}$ & $15,77 \mathrm{Aa}$ & $0,45 \mathrm{Ac}$ \\
\hline Xaraés & $2,97 \mathrm{Bb}$ & $11,92 \mathrm{ABa}$ & $0,45 \mathrm{Ab}$ \\
\hline CV (\%) & & 20,19 & \\
\hline
\end{tabular}

Médias seguidas pela mesma letra maiúscula para cultivares de Brachiaria brizantha e minúscula para disponibilidades hídricas não diferem entre si pelo teste Tukey a 0,05 de probabilidade; CV (\%) - Coeficiente de variação 
Tabela 4. Relação MSF/MSC no primeiro e no terceiro corte das cultivares de Brachiaria brizantha sob diferentes disponibilidades hídricas do solo

\begin{tabular}{|c|c|c|c|}
\hline & \multicolumn{3}{|c|}{ Disponibilidade hídrica } \\
\hline & Alagado & Capacidade de campo & Déficit hídrico \\
\hline & & $1^{\circ}$ Corte & \\
\hline Relação MSF/MSC & $2,49 \mathrm{~B}$ & $1,95 \mathrm{~B}$ & $5,18^{a}$ \\
\hline CV $(\%)$ & & 19,42 & \\
\hline & & $3^{\circ}$ Corte & \\
\hline $\begin{array}{l}\text { Relação MSF/MSC } \\
\text { CV (\%) }\end{array}$ & $1,35 \mathrm{~A}$ & $\begin{array}{l}1,81 \mathrm{~A} \\
14,40\end{array}$ & $0,36 \mathrm{~B}$ \\
\hline
\end{tabular}

Médias seguidas pela mesma letra maiúscula não diferem entre si pelo teste Tukey a 0,05 de probabilidade; CV (\%) - Coeficiente de variação

condições alagadas quando comparadas à capacidade de campo (10 kPa) (Tabela 2).

Estudos de produção de massa seca de folhas em gramíneas forrageiras são importantes em razão das folhas se constituírem no órgão das plantas preferencialmente consumidas pelos animais além de ser a principal fonte de nutrientes para os ruminantes em sistema de pastejo (Rodrigues et al., 2008).

No segundo e no terceiro corte das gramíneas forrageiras (Tabela 2) também ocorreu decréscimo na massa seca de folhas em condições de déficit hídrico e no solo alagado, quando comparadas à capacidade de campo, exceto para a cultivar Marandu em que não se observou diferença na massa seca de folhas das plantas cultivadas no solo alagado em relação ao tratamento na capacidade de campo, o que demonstra resistência desta cultivar ao alagamento do solo.

Tal resultado diverge de um dos primeiros estudos publicados no Brasil por Dias-Filho \& Carvalho (2000) que indicavam a cv. Marandu com baixa tolerância ao alagamento e de Mattos et al. (2005) que verificam que a taxa de crescimento das folhas em B. brizantha, cv. Marundu foi maior em déficit hídrico do que sob alagamento; entretanto, a mesma cultivar pode ter genótipos diferentes ocorrendo variação intraespecífica na tolerância ao estresse hídrico (Silva et al., 2009) uma vez que plantas mais adaptadas às condições adversas modificam a maioria de suas funções fisiológicas para manter suas atividades vitais, o que pode ter ocorrido com a cultivar utilizada.

Pode-se observar que as três cultivares de Brachiaria brizantha apresentaram menor produção de massa seca de folhas em condição de estresse por déficit hídrico quando comparadas com as condições de alagamento do solo.

Em relação à massa seca de colmos observou-se efeito significativo das disponibilidades hídricas do solo nos primeiro, segundo e terceiro cortes das gramíneas forrageiras. Nota-se que a menor produção ocorreu nas plantas cultivadas sob déficit hídrico, independentemente da cultivar de Brachiaria (Tabela 3).

Em condições de solo alagado a cultivar Marandu produziu a maior massa seca de colmos nos três cortes, seguida pela cultivar Piatã; este resultado diverge dos encontrados por Caetano \& Dias-Filho (2008) ao verificar que o alagamento do solo diminuiu o número de perfilhos nas cultivares Marandu, classificando esta cultivar como pouco tolerante ao alagamento (Dias-Filho, 2002). Contudo, Ramos et al. (2011) constataram, analisando respostas fisiológicas e metabólicas de gramíneas (Brachiaria brizantha e Paspalum fasciculatum) ao alagamento, que a deficiência de oxigênio causada pelo alagamento induziu as espécies estudadas a um ajustamento metabólico e fisiológico que permitiu, às plantas, sobreviverem nesta condição desfavorável porém, a espécie Paspalum fasciculatum mostrou ser mais adaptada ao alagamento.

As cultivares Marandu e Piatã são sensíveis ao déficit hídrico porém, apresentam sistema radicular profundo que é um mecanismo de adaptação de plantas tolerantes ao estresse hídrico (Santos et al., 2013).

Pezzopane et al. (2014) observaram, avaliando as cultivares BRS Piatã, Marandu, Xaraés e BRS Paiaguás, com e sem déficit hídrico, que esses genótipos de Brachiaria brizantha apresentam comportamento semelhante com relativa tolerância à seca porém, a BRS Piatã se destacou com menor porcentagem de redução de desenvolvimento. Mattos et al. (2005) justificaram, associando as cultivares de B. brizantha com maior tolerância ao déficit hídrico, que isto ocorre pela menor sensibilidade de seus estômatos ao estresse, o que acarreta menor comprometimento de suas taxas de fotossíntese.

Endres et al. (2010) relatam que a redução da fotossíntese é mais rápida que a redução da taxa respiratória; para tanto, há uma consequente diminuição na produção de massa seca supondo-se que, possivelmente, as plantas de Brachiaria brizantha cultivadas sob condições de déficit hídrico tiveram suas taxas fotossintéticas reduzidas devido a esse estresse, acarretando diminuição de fotoassimilados responsáveis pelo desenvolvimento da planta, o que corrobora com a redução da massa seca de colmos das plantas de Brachiaria brizantha cultivadas sob déficit hídrico.

$\mathrm{Na}$ relação massa seca de folhas/massa seca de colmos (MSF/MSC) não houve diferença estatística entre as cultivares analisadas sendo significativas apenas para disponibilidades hídricas. Segundo Wilson (1982) a relação MSF/MSC é uma variável de grande importância para a nutrição mineral e para o manejo das plantas forrageiras. Alta relação MSF/ MSC representa forragem de elevado teor de proteína, digestibilidade e consumo, capaz de atender às exigências nutricionais dos ruminantes garantindo maior ganho de peso ou produção de leite pelos animais.

Ainda segundo Pinto et al. (1994) a alta relação MSF/MSC confere, à gramínea, melhor adaptação ao pastejo ou tolerância ao corte por apresentar um momento fenológico em que os meristemas apicais se apresentam mais próximos ao solo e, portanto, menos vulneráveis à destruição pelo corte animal ou máquina. Ressaltam ainda que o limite crítico da relação folha/ colmo é considerado igual a 1,00 e este nível crítico considera a quantidade e a qualidade da forragem produzida.

No primeiro corte a maior relação MSF/MSC foi observada nos tratamentos com as plantas sob déficit hídrico, mas no segundo corte a relação não foi significativa. No entanto, no terceiro corte não houve diferença na relação MSF/MSC para o solo alagado em relação à capacidade de campo (Tabela 4). Ressalta-se que a relação MSF/MSC encontrada foi superior à relação crítica (1:1) relatada por Pinto et al. (1994).

A maior relação MSF/MSC no primeiro corte das plantas sob déficit hídrico pode ter ocorrido em virtude das plantas nos estádios iniciais de crescimento serem constituídas basicamente por folhas em detrimento do colmo. Segundo Rodrigues et al. (2008) no desenvolvimento inicial das 
gramíneas forrageiras a produção de massa seca é composta basicamente de folhas. Esta maior proporção de folhas pode ser atribuída à necessidade que a planta apresenta em produzir substâncias necessárias para seu desenvolvimento aumentando a área fotossintética (Nussio et al., 1998).

No terceiro corte, a baixa relação MSF/MSC com déficit hídrico foi resultado da baixa produção das folhas (Tabela 1). A relação MSF/MSC de gramíneas forrageiras tem grande relevância para a nutrição animal e para o manejo das plantas visto que a maior participação de folhas ou hastes na composição da massa seca altera o valor nutritivo da forragem consumida. A alta relação MSF/MSC representa forragem de elevado teor de proteína, digestibilidade e consumo (Hacker, 1982).

\section{Conclusões}

1. As cultivares de Brachiaria brizantha (Marandu, Piatã e Xaraés) cultivadas em Neossolo Flúvico são susceptíveis ao déficit hídrico do solo quanto à massa seca de folhas, massa seca de colmos e relação folha/colmo.

2. A cultivar Marandu foi a única cultivar resistente ao alagamento do solo com bom desenvolvimento nos três cortes realizados.

3. As disponibilidades hídricas no Neossolo Flúvico influenciam a produção das cultivares de Brachiaria brizantha, sendo o déficit hídrico a disponibilidade que acarreta em menor desenvolvimento das cultivares.

\section{Literatura Citada}

Almeida, A. S.; Araújo, F. S.; Souza, G. S. Determinação da curva parcial de retenção de água de um Latossolo Vermelho por tensiometria. Scientia Plena, v.6, p.1-5, 2010.

Araújo, S. A. do C.; Vasquez, H. M.; Campostrini, E.; Netto, A. T.; Deminicis, B. B.; Lima, É. da S. Características fotossintéticas de genótipos de capim-elefante anão (Pennisetum purpureum Schum), em estresse hídrico. Acta Scientiarum. Animal Sciences, v.32, p.1-7, 2010.

Caetano, L. P. de S.; Dias-Filho, M. B. Responses of six Brachiaria spp. accessions to root zone flooding. Revista Brasileira de Zootecnia, v.37, p.795-801, 2008. http://dx.doi.org/10.1590/ S1516-35982008000500003

Carvalho, F. E. L.; Lobol, A. K. M.; Bonifácio, A.; Martins, M. O.; Lima Neto, M. C.; Silveira, J. A. G. Aclimatação ao estresse salino em plantas de arroz induzida pelo pré-tratamento com $\mathrm{H}_{2} \mathrm{O}_{2}$. Revista Brasileira de Engenharia Agrícola e Ambiental, v.15, p.416-423, 2011. http://dx.doi.org/10.1590/S1415-43662011000400014

Dias-Filho, M. B. Tolerância ao alagamento em cinco acessos de Brachiaria brizantha. Pesquisa Agropecuária Brasileira, v.37, p.439-447, 2002. http://dx.doi.org/10.1590/S0100204X2002000400003

Dias-Filho, M. B.; Carvalho, C. J. de. Physiological and morphological responses of Brachiaria spp. to flooding. Pesquisa Agropecuária Brasileira, v.35, p.1959-1966, 2000. http://dx.doi.org/10.1590/ S0100-204X2000001000006

Dias-Filho, M. B; Lopes, M. J. S. Triagem de forrageiras para tolerância ao excesso de água no solo. Belém: Embrapa Amazônia Oriental, 2012, 31p.
Duarte, J. M. de L.; Lima, A. D.; Nascimento, R. S.; Viana, T. V. de A.; Saraiva, K. R.; Azevedo, B. M. de. Eficiência do uso da água na produção de óleo do girassol (Helliantus annuus L.) sob suspensão hídrica. Revista Brasileira de Agricultura Irrigada, v.6, p.166-175, 2012. http://dx.doi.org/10.7127/rbai.v6n300081

EMBRAPA - Empresa Brasileira de Pesquisa Agropecuária. Manual de métodos de análise de solo. Rio de Janeiro: Centro Nacional de Pesquisa de Solos. 2.ed. 1997. 212p.

EMBRAPA - Empresa Brasileira de Pesquisa Agropecuária. Sistema brasileiro de classificação de solos. Rio de Janeiro: Centro Nacional de Pesquisa de Solos. 2006. 306p.

Endres, L.; Souza, J. L. de; Teodoro, I.; Marroquim, P. M. G.; Santos, C. M.; Britos, J. E. D. Gas exchange alteration caused by water deficit during the bean reproductive stage. Revista Brasileira de Engenharia Agrícola e Ambiental, v.14, p.11-16, 2010. http:// dx.doi.org/10.1590/S1415-43662010000100002

Hacker, J. B. Nitritional limits to animal production from pastures. Wallingford: CAB, 1982. p.111-113.

IBGE - Instituto Brasileiro de Geografia e Estatística. http://<www. ibge.gov.br> Mapa de 2011. 25 Ago 2013.

Jones, C. A. The potential of Andropogon gayanus Kunth in the oxsols and ultisols savannas of tropical America. Herbage Abstract, v.49, p.1-8, 1979.

MAPA - Ministério da Agricultura Pecuária e Abastecimento. Projeções do Agronegócio: Brasil 2012/2013 a 2022/2023/ Ministério da Agricultura, Pecuária e Abastecimento. Assessoria de Gestão Estratégica. Brasília: MAPA/ACS, 2013. 96p.

Mattos, J. L. S.; Gomide, J. A.; Martinez y Huaman, C. A. Crescimento de espécies de Brachiaria sob déficit hídrico e alagamento a campo. Revista Brasileira de Zootecnia, v.34, p.755-764, 2005. http:// dx.doi.org/10.1590/S1516-35982005000300006

Nussio, L. G.; Manzano, R. P.; Pedreira, C. G. S. Valor alimentício em plantas do gênero Cynodon. In: Simpósio sobre manejo da pastagem, 15, 1998. Anais...Piracicaba: FEALQ: 1998. CD-Rom

Pezzopane, C. de G.; Santos, P. M.; Cruz, P. G. da; Altoé, J.; Ribeiro, F. A.; Valle, C. B. do. Estresse por deficiência hídrica em genótipos de Brachiaria brizantha. Ciência. Rural, v.00, p.00-00, 2014.

Pinto, J. C.; Gomide, J. A.; Maestri, M. Produção de matéria seca e relação folha/caule de gramíneas forrageiras tropicais cultivadas em vaso, com duas doses de nitrogênio. Revista da Sociedade Brasileira de Zootecnia, v.23, p.313-326, 1994.

Ramos, T. J. N.; Souza, C. M. A.; Carvalho, C. J. R.; Vieira, I. M. S. Respostas fisiológicas e metabólicas de gramíneas ao alagamento. Revista de Ciências Agrárias, v.54, p.78-84, 2011. http://dx.doi. org/10.4322/rca.2011.041

Rodrigues, R. C.; Mourão, G. B.; Brennecke, K.; Luz, P. H. DE C.; Herling, V. R. Produção de massa seca, relação folha/colmo e alguns índices de crescimento do Brachiaria brizantha cv. Xaraés cultivado com a combinação de doses de nitrogênio e potássio. Revista Brasileira de Zootecnia, v.37, p.394-400, 2008. http:// dx.doi.org/10.1590/S1516-35982008000300003

Santos, P. M.; Cruz, P. G.; Araujo, L. C.; Ricardo, J.; Pezzopane, M.; Valle, C. B.; Pezopane, C. G. Response mechanisms of Brachiaria brizantha cultivars to water deficit stress. Revista Brasileira de Zootecnia, v.42, p.767-773, 2013. http://dx.doi.org/10.1590/ S1516-35982013001100001 
Silva, A. S.; Laura, V. A.; Jank, L. Soil Flood Tolerance of Seven Genotypes of Panicum maximum Jacq. Brazilian Archives of Biology and Technology, v.52, p.1341-1348, 2009. http://dx.doi. org/10.1590/S1516-89132009000600004

Silva, E. M. B.; Monteiro, F. A.; Silva, T. J. A. Nitrogênio e enxofre na produção e no uso de água pelo capim-braquiária em degradação. Revista Brasileira de Ciência do Solo, v.31, p.909-317, 2007.

Silva, F. de A. S. e; Azevedo.; C. A. V. de. Versão do programa computacional Assistat para o sistema operacional Windows. Revista Brasileira de Produtos Agroindustriais, v.4, p.71-78, 2002.

Visser, E. J. W.; Voesenek, L. A. C. J.; Vartapetian, B. B.; Jackson, M. B. Flooding and Plant Growth. Annals of Botany, London, v.91, p.107-109, 2003. http://dx.doi.org/10.1093/aob/mcg014
Vitor, C. M. T.; Fonseca, D. M.; Cóser, A. C. Produção de matéria seca e valor nutritivo de pastagem de capim-elefante sob irrigação e adubação nitrogenada. Revista Brasileira de Zootecnia, v.38, p.435-442, 2009. http://dx.doi.org/10.1590/ S1516-35982009000300006

Wilson, J. R. Environmental and nutritional factores affecting herbage quality. In: Hacker, J.B. (ed.) Nutritional limits to production from pastures. Farnham Royal: CAB, p.111-131, 1982.

Zimmer, A. H.; Euclides, V. P. B. Importância das pastagens para o futuro da pecuária de corte no Brasil. In: Simpósio de Forragicultura e Pastagem, 1, 2000, Lavras. Anais...Lavras: Universidade Federal de Lavras, 2000. p.1-49. 